\title{
Preparation of Biocompatible Carboxymethyl Chitosan Nanoparticles for Delivery of Antibiotic Drug
}

\author{
Liang Zhao, ${ }^{1}$ Bingya Zhu, ${ }^{1}$ Yunhong Jia, ${ }^{1}$ Wenjiu Hou, ${ }^{2}$ and Chang Su${ }^{2}$ \\ ${ }^{1}$ College of Pharmacy, Liaoning Medical University, Jinzhou 121000, China \\ ${ }^{2}$ College of Veterinary Medicine, Liaoning Medical University, Jinzhou 121000, China \\ Correspondence should be addressed to Chang Su; changsu80@163.com
}

Received 4 January 2013; Revised 10 February 2013; Accepted 13 February 2013

Academic Editor: John B. Vincent

Copyright (c) 2013 Liang Zhao et al. This is an open access article distributed under the Creative Commons Attribution License, which permits unrestricted use, distribution, and reproduction in any medium, provided the original work is properly cited.

\begin{abstract}
Objective. To prepare biocompatible ciprofloxacin-loaded carboxymethyl chitosan nanoparticles (CCC NPs) and evaluate their cell specificity as well as antibacterial activity against Escherichia coli in vitro. Methods. CCC NPs were prepared by ionic cross-linking method and optimized by using Box-Behnken response surface method (BBRSM). Zeta potential, drug encapsulation, and release of the obtained nanoparticles in vitro were thoroughly investigated. Minimum inhibitory concentration (MIC) and killing profiles of free or ciprofloxacin-loaded nanoparticles against Escherichia coli were documented. The cytotoicity of blank nanoparticles and cellular uptake of CCC NPs were also investigated. Results. The obtained particles were monodisperse nanospheres with an average hydrated diameter of $151 \pm 5.67 \mathrm{~nm}$ and surface of charge $-22.9 \pm 2.21 \mathrm{mV}$. The MICs of free ciprofloxacin and CCC NPs were 0.16 and $0.08 \mu \mathrm{g} / \mathrm{mL}$, respectively. Blank nanoparticles showed no obvious cell inhibition within $24 \mathrm{~h}$, and noticeable phagocytosis effect was observed in the presence of CCC NPs. Conclusion. This study shows that CCC NPs have stronger antibacterial activity against Escherichia coli than the free ciprofloxacin because they can easily be uptaken by cells. The obtained CCC NPs have promising prospect in drug delivery field.
\end{abstract}

\section{Introduction}

Ciprofloxacin (CPFX), as one outstanding representative of the third generation of fluoroquinolone antimicrobials with broad antibacterial spectrum, strong antibacterial activity, and low effective inhibition concentration, has achieved numerous satisfactory results in clinical applications [1, 2]. The formulations of CPFX such as capsule, tablet, and injection have been widely used [3, 4]. However, these ordinary administration methods show that the highest bioavailability of the drug is approximately $52 \%$. In addition, half-life of the useable CPFX is too short to realize prolonged drug release. Although many pathogens can be directly internalized into cells, most of drugs will be degraded by lysosome before killing bacteria. This phenomenon usually leads to the low intracellular drug concentration. The cells infected provide a huge storage in which pathogenic microbes and bacteria are propagated and amplified. Release of pathogenic bacteria often leads to recurrence of controlled infecting symptoms $[5,6]$. Chitosan, as a good biodegradable, natural originated material, has been widely used as the sustained drug-release carrier in pharmaceutical field [7-9]. Carboxymethyl chitosan (CMC) is obtained by carboxylation reaction of amine group substitution by small alkyl groups. CMC is biocompatible and easy to degradation. Compared with chitosan, CMC has good solubility in water without aid of acid substance, thus avoiding the damage in $\mathrm{pH}$ sensitive drug antibacterial activity $[10,11]$. Herein, in the present work, carboxymethyl chitosan nanoparticles were prepared by ionic cross-linking method to improve the cell uptake of drug efficacy and to prolong the acting time of the drug.

\section{Experimental}

2.1. Materials. Carboxymethyl chitosan (CMC) was obtained from Haixin Biological Product Co., Ltd (China), ciprofloxacin (98.7\%) Zhejiang Jingxin Pharmaceutical Co., Ltd (China), and Escherichia coli ATCC-25922 was purchased from Nanjing Bianzhen Biotechnology Co., Ltd (China). Fluorescein isothiocyanate (FITC) and aluminum chloride 
were obtained from Sigma Chemicals (St Louis, USA). All the other used chemicals were of analytical grade.

2.2. Preparation of CCC NPs. $0.05 \mathrm{~g}$ of carboxymethyl chitosan was dissolved in $50 \mathrm{~mL}$ deionized water, stirring and swelling overnight. Deionized water solution containing ciprofloxacin was dripped into the carboxymethyl chitosan solution and continued stirring for $2 \mathrm{~h}$. Aluminum chloride reserve liquid $(0.1 \mathrm{mg} / \mathrm{mL})$ was prepared and filtrated through $0.45 \mu \mathrm{m}$ filter. CCC NPs were prepared by dropping $\mathrm{AlCl}_{3}$ reserve liquid quickly into the system at certain temperature and continuously stirred for $1 \mathrm{~h}$ until milk light appeared. CCC NPs collected were washed 3-4 times with deionized water and centrifuged at $16000 \mathrm{rpm}$ for $20 \mathrm{~min}$, freeze-drying to obtain powders.

2.3. Experiment Design and Data Processing. Box-Behnken design as a type of response surface method has been applied to pharmaceutical systems and particulate carriers. It provides detailed information to better understand potential interaction between various factors employed in pharmaceutical preparations for yielding the optimal formulation [12, 13]. Experiments were designed according to Box-Behnken response surface method and shown in Table 1 . The selected factors were as follows: drug/carboxymethyl chitosan $\left(X_{1}\right)$, reacting temperature $\left(X_{2}\right)$, and the amount of $\mathrm{AlCl}_{3}\left(X_{3}\right)$. CCC NPs were prepared, and their loading and encapsulation efficiency as response values were determined. Each response value was standardized between $0 \sim 1$ as the normalized value by using Hassan method, and all normalized values were used to calculate the geometric mean and get general normalized value (OD) [14]. The formula was as follows:

$$
\begin{gathered}
\mathrm{OD}_{i}=\left(d_{i} f_{i}\right)^{1 / 2} \\
d_{i}=\frac{\left(Y_{i}-Y_{\min }\right)}{\left(Y_{\max }-Y_{\min }\right)} \\
f_{i}=\frac{\left(Z_{i}-Z_{\min }\right)}{\left(Z_{\max }-Z_{\min }\right)},
\end{gathered}
$$

where $i$ represents the total test points from 1 to 17.

2.4. Characterization of CCC NPs. 1 2 drops of CCC NPs solution were placed in a supporting copper film and stained using phosphotungstic acid. After drying, morphology of the nanoparticles was observed by transmission electron microscope (JEM-1200EX, Tokyo, Japan). CCC NPs solution was diluted with deionized water to the appropriate concentration and measured by Zetasizer (Nano ZS90, Malvern, UK) for determining hydrated swelling size distribution and surface charge.

2.5. Determination of Drug Loading and Encapsulation Efficiency. The total mass amount of CCC NPs was accurately weighed, and $2 \mathrm{mg}$ sample of CCC NPs was dispersed in $10 \mathrm{~mL} 0.01 \mathrm{~mol} / \mathrm{L} \mathrm{HCL}$ under ultrasonic extraction for $0.5 \mathrm{~h}$. The obtained mixture was filtered through a $0.45 \mu \mathrm{m}$
TABLE 1: Design scheme and response values.

\begin{tabular}{lcccccc}
\hline $\begin{array}{l}\text { Formulation } \\
\text { code }\end{array}$ & $X_{1}{ }^{\mathrm{a}}$ & $X_{2}{ }^{\mathrm{b}}$ & $X_{3}{ }^{\mathrm{c}}$ & $\mathrm{LE} \%(Y)^{\mathrm{d}}$ & $\mathrm{EE} \%(Z)^{\mathrm{e}}$ & $\mathrm{OD}^{\mathrm{f}}$ \\
\hline 1 & 0.18 & 45.00 & 4.00 & 5.76 & 58.27 & 0.61 \\
2 & 0.12 & 55.00 & 5.00 & 3.71 & 85.52 & 0.70 \\
3 & 0.06 & 45.00 & 5.00 & 5.89 & 48.29 & 0.43 \\
4 & 0.18 & 55.00 & 4.50 & 5.33 & 43.48 & 0.27 \\
5 & 0.18 & 35.00 & 4.50 & 6.24 & 51.68 & 0.52 \\
6 & 0.12 & 35.00 & 4.00 & 5.08 & 68.29 & 0.69 \\
7 & 0.18 & 45.00 & 5.00 & 3.36 & 39.25 & 0 \\
8 & 0.12 & 45.00 & 4.50 & 4.85 & 53.42 & 0.47 \\
9 & 0.06 & 55.00 & 4.50 & 1.53 & 58.38 & 0.13 \\
10 & 0.12 & 45.00 & 4.50 & 4.88 & 53.42 & 0.47 \\
11 & 0.06 & 45.00 & 4.00 & 1.31 & 49.30 & 0 \\
12 & 0.12 & 45.00 & 4.50 & 4.76 & 54.65 & 0.48 \\
13 & 0.12 & 55.00 & 4.00 & 4.19 & 58.44 & 0.49 \\
14 & 0.12 & 45.00 & 4.50 & 4.55 & 55.21 & 0.48 \\
15 & 0.06 & 35.00 & 4.50 & 2.01 & 55.08 & 0.22 \\
16 & 0.12 & 35.00 & 5.00 & 4.00 & 70.23 & 0.60 \\
17 & 0.12 & 45.00 & 4.50 & 4.66 & 55.04 & 0.48 \\
\hline
\end{tabular}

${ }^{\mathrm{a}}$ Drug/carboxymethyl chitosan, weight/weight; ${ }^{\mathrm{b}}$ reacting temperature, ${ }^{\circ} \mathrm{C}$; ${ }^{c}$ added amount of $\mathrm{AlCl}_{3}$; ${ }^{\mathrm{d}}$ loading efficiency; ${ }^{\mathrm{e}}$ encapsulation efficiency; ${ }^{\mathrm{f}}$ general normalized value.

millipore filter for determining absorbance of the filtrate at $277 \mathrm{~nm}$ using a UV/Vis spectrophotometer (model 1601, Shimadzu, Japan). Loading efficiency (LE, \%) and encapsulation efficiency (EE, \%) were calculated using (2):

$$
\begin{aligned}
& \mathrm{LE}(\%)=\frac{\text { amount of CPFX in NPs }}{\text { weight of NPs }} \times 100 \\
& \mathrm{EE}(\%)=\frac{\text { amount of CPFX in NPs }}{\text { Initially added CPFX }} \times 100 .
\end{aligned}
$$

2.6. Investigation of Drug Release Behavior. Accurate weighed $10 \mathrm{mg}$ CCC NPs wrapped in a dialysis bag (spectrum, USA) were placed in $30 \mathrm{~mL}$ phosphate buffer solution $(\mathrm{pH}=7.4)$. The temperature was maintained at $37.0 \pm 0.5^{\circ} \mathrm{C}$ and the stirring speed at $100 \mathrm{rpm} .3 \mathrm{~mL}$ of buffer solution was taken out at $0.5,1,2,3,4,6,8,10,12$, and $24 \mathrm{~h}$, and $3 \mathrm{~mL}$ fresh phosphate buffer solution $(\mathrm{pH}=7.4)$ was added to maintain the release medium volume at the same time. Samples were filtered through $0.45 \mu \mathrm{m}$ filter and analyzed spectrophotometrically at $277 \mathrm{~nm}$.

2.7. Antibacterial Determination of CPFX and CCC NPs against Escherichia coli ATCC-25922. CPFX and CCC NPs were diluted with LB culture medium to $10.24,5.12,2.56$, $1.28,0.64,0.32,0.16$, and $0.08 \mu \mathrm{g} / \mathrm{mL}$ ( 8 levels) calculated by the concentration of CPFX and $100 \mu \mathrm{L}$ from each level was added into 96 -well plate. $100 \mu \mathrm{L}$ of bacteria liquid was added into wells containing different concentration of CPFX, and the number of Escherichia coli ATCC-25922 in well was $1 \times$ $10^{6} \mathrm{CFU} / \mathrm{mL}$. LB culture medium without CPFX was also 
TABLE 2: Analysis of variance in RSM.

\begin{tabular}{lccccc}
\hline Source & Sum of squares & df & Mean square & $F$ value & $\begin{array}{c}P \text { value } \\
\text { probe }>F\end{array}$ \\
\hline Model & 0.72 & 9 & 0.080 & 20.79 & 0.0003 \\
$X_{1}$ & 0.048 & 1 & 0.048 & 12.45 & 0.0096 \\
$X_{2}$ & 0.024 & 1 & 0.024 & 6.27 & 0.0408 \\
$X_{3}$ & $4.500 E-004$ & 1 & $4.500 E-004$ & 0.12 & 0.7428 \\
$X_{1} X_{2}$ & $6.400 E-003$ & 1 & $6.400 E-003$ & 1.66 & 0.2388 \\
$X_{1} X_{3}$ & 0.27 & 1 & 0.27 & 70.05 & $<0.0001$ \\
$X_{2} X_{3}$ & 0.022 & 1 & 0.022 & 5.83 & 0.0465 \\
$X_{1}{ }^{2}$ & 0.32 & 1 & 0.32 & 82.79 & $<0.0001$ \\
$X_{2}{ }^{2}$ & 0.030 & 1 & 0.030 & 7.79 & 0.0269 \\
$X_{3}{ }^{2}$ & 0.015 & 1 & 0.015 & 3.86 & 0.0901 \\
Residual & 0.027 & 7 & $3.860 E-003$ & & \\
Lack of fit & 0.027 & 3 & $8.967 E-003$ & 298.89 & $<0.0001$ \\
Pure error & $1.200 E-004$ & 4 & $3.000 E-005$ & & \\
\hline Cor total & 0.75 & 16 & \multicolumn{3}{l}{} \\
\hline$P<0.001$ is highly significant: $P<0.05$ is significant.
\end{tabular}

used to inoculate bacteria under the same method as blank control. The sample was incubated at $37^{\circ} \mathrm{C}$ and removed after $20 \mathrm{~h}$, then determining the lowest concentrations of no bacterial growth as minimum inhibitory concentration (MIC).

Each $1.5 \mathrm{~mL}$ solution of free CPFX and CCC NPs diluted with LB culture medium to $0.16 \mu \mathrm{g} / \mathrm{mL}$ of CPFX was added to test tubes followed by the addition of $1.5 \mathrm{~mL}$ bacteria liquid in which concentration of bacterial colony was $2 \times 10^{6} \mathrm{CFU} / \mathrm{mL}$. Samples were cultured in the incubator and drug-free tube was set (liquid $1.5 \mathrm{~mL}+$ medium $1.5 \mathrm{~mL}$ ) as blank control. $10 \mu \mathrm{L}$ of samples was removed at $1,2,4,6$, and $8 \mathrm{~h}$ to count colony. Curve was made from logarithm of colony number against different culturing time.

2.8. Cell Viability Assays. SMMC-7221 liver carcinoma cells were seeded into each well of a 96-well cell culture plate. After culturing for $24 \mathrm{~h}$, nanoparticles without CPFX were added into the exposed cells, and concentrations calculated by $\mathrm{CMC}$ were $0.1,0.2,0.4,0.8,1.2,1.8$, and $2.4 \mathrm{mg} / \mathrm{mL}$. After culturing for $24 \mathrm{~h}$, 96-well cell culture plate was taken out. $10 \mu \mathrm{L}$ four methyl thiazolyl tetrazolium salt (MTT) was added to $10 \mu \mathrm{L}$ culture medium from each well and continued culturing. Cultural supernatant was discarded and $100 \mu \mathrm{L}$ (sodium dodecyl sulfate) SDS- $\mathrm{HCl}$ was placed in each well overnight. ELISA meter (model 2550, Biorad, USA) was applied and the absorbance value was measured at $570 \mathrm{~nm}$.

2.9. In Vitro Cellular Uptake of CCC NPs. SMMC-7221 liver carcinoma cells $\left(2 \mathrm{~mL}, 5 \times 10^{5} / \mathrm{mL}\right)$ were seeded to 6 -well plates and were cultured overnight. CCC NPs encapsulating FITC were added into the medium and incubated for $8 \mathrm{~h}$. After centrifugation the supernatant was discarded and cells in well were washed with ice-cold PBS for 3 times. Finally cells were observed by fluorescence microscope.

\section{Results}

3.1. The Result of RSM. The result in regression variance analysis and significance test in the model is shown in Table 2. Lack of fit in the model was 298.89, $P<0.0001$, and showed extremely significant difference among models. Model determination coefficient $R_{\text {adj }}^{2}$ value was 0.9176 and showed that there was linear relationship between the dependent variables and all independent variables. The variance analysis of regression model also displayed that $X_{1}, X_{2}$ were significant, and the interaction term $X_{1} X_{3}$, a square term $X_{1}^{2}$, demonstrated high significance. $F$ value of the model is 20.79 and the probability of $P<0.0005$, which indicated that the model had a high fitting degree. A multiple linear regression equation on the relationship between selected factors and general normalized value OD is established as

$$
\begin{aligned}
\mathrm{OD}= & +0.48+0.077 X_{1}-0.055 X_{2} \\
& -7.500 \mathrm{E}-003 X_{3}-0.040 X_{1} X_{2} \\
& -0.26 X_{1} X_{3}+0.075 X_{2} X_{3} \\
& -0.28 X_{1}^{2}+0.085 X_{2}^{2}+0.060 X_{3}^{2} .
\end{aligned}
$$

3.2. Response Surface Analysis. 3D figures of response surface designed by using OD as the dependent variable and two actors as variables are shown in Figure 1. OD value was increased with the increase of the ratio of drug/carboxymethyl chitosan. When the ratio of drug/carboxymethyl chitosan was 0.16, the OD value was the highest. After that, $\mathrm{OD}$ value was reduced with the increase of the ratio of drug/carboxymethyl chitosan. In terms of reacting temperature, OD value showed first decrease and then an upward trend in the range of $35-55^{\circ} \mathrm{C}$. As the effect of amount of $\mathrm{AlCl}_{3}$ on $\mathrm{OD}$ value was not significant, any amount should be applied between 4.0 and $5.0 \mathrm{mg}$. The optimal formulation of CCC NPs by using RSM was concluded as follows: when the ratio of drug/carboxymethyl chitosan was 0.16 , reacting temperature was $35^{\circ} \mathrm{C}$, and the amount of $\mathrm{AlCl}_{3}$ was $4.0 \mathrm{mg}$, the predicted OD was $88.7 \%$. Drug loading efficiency was $(76.0 \pm 4.31) \%$, drug encapsulation efficiency was $(92.3 \pm$ $7.21) \%$, and OD was $(83.8 \pm 5.11) \%$. Model predicting results were close to actual data, demonstrating that established model was reliable.

3.3. Appearance of CCC NPs. Figure 2 shows that under the optimized condition, the obtained CCC NPs are spherical pellets with good monodispersity and homogenous particle size at average hydrated diameter of $151 \pm 5.67 \mathrm{~nm}$ and surface charge of $-22.9 \pm 2.21 \mathrm{mV}$ measured by Zetasizer.

3.4. In Vitro Drug Release. Figure 3 shows that CCC NPs have obvious sustained drug release behavior. About 9\%-27\% of total drug was released rapidly at first $0.5 \mathrm{~h}$ and more than $95 \%$ released in $24 \mathrm{~h}$. Results of release in vitro by using release kinetics models were fitted, trying to find the best drug release model. 


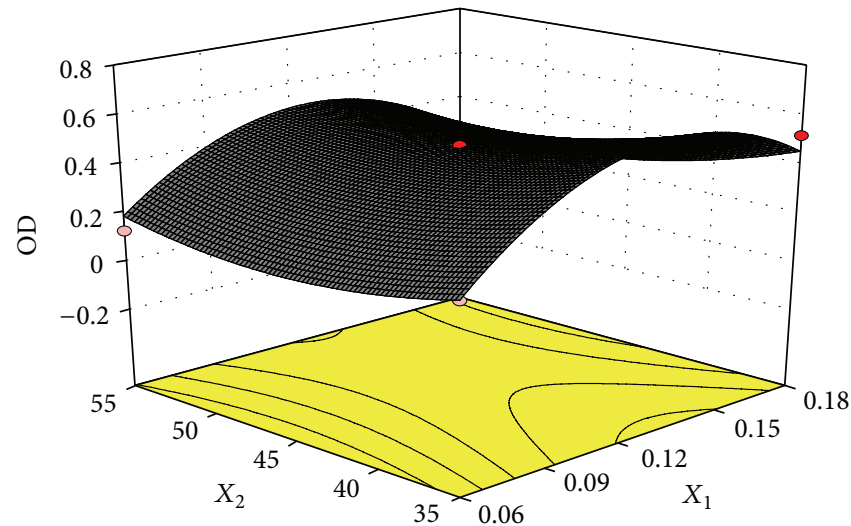

(a)

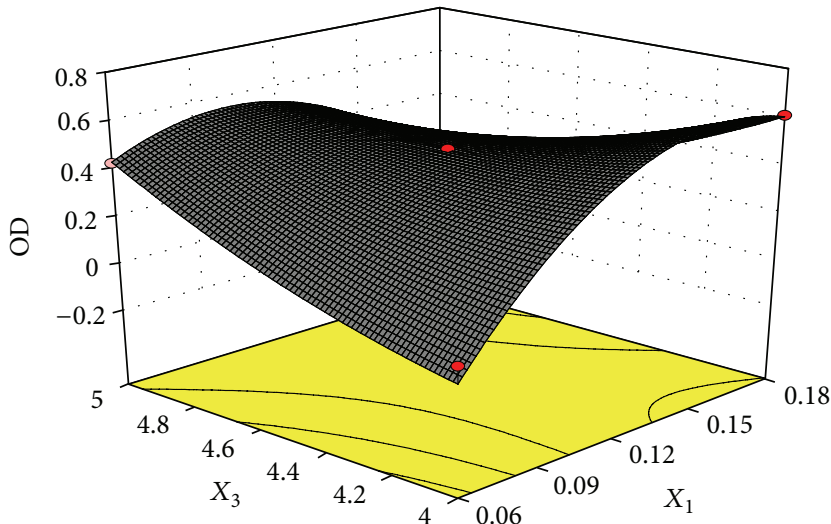

(b)

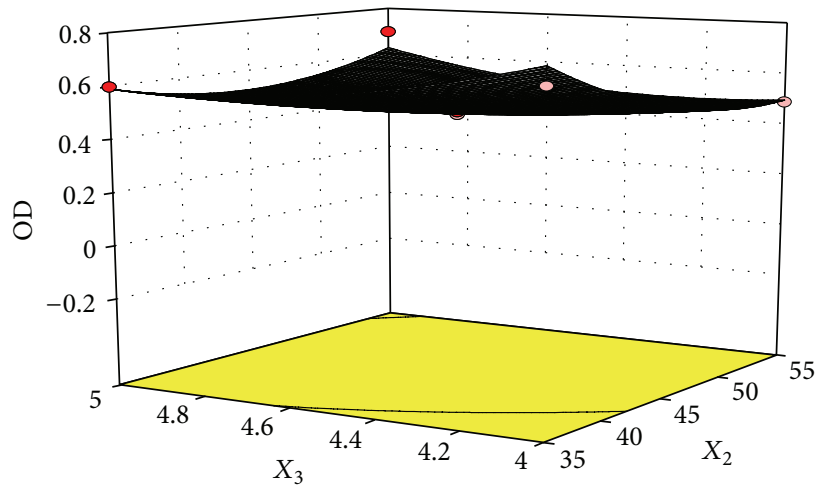

(c)

Figure 1: Effects of $X_{1}-X_{2}$ (I), $X_{1}-X_{3}$ (II), and $X_{2}-X_{3}$ (III) on OD $\left(X_{1}\right.$ : mass ratio between drug and carboxymethyl chitosan, $X_{2}$ : reacting temperature, $X_{3}$ : amount of $\left.\mathrm{AlCl}_{3}\right)$.

TABLE 3: Regression results of equations in vitro release from CCC NPs.

\begin{tabular}{lccccccccc}
\hline & \multicolumn{2}{c}{ Zero-order } & \multicolumn{2}{c}{ First-order } & \multicolumn{2}{c}{ Higuchi } & \multicolumn{2}{c}{ Ritger-Peppas } & \multicolumn{2}{c}{ Double exponential } \\
Code & \multicolumn{2}{c}{$Q_{t}=K t$} & \multicolumn{2}{c}{$\ln \left(1-Q_{t}\right)=K t$} & \multicolumn{2}{c}{$Q_{t}=K t^{1 / 2}$} & \multicolumn{2}{c}{$Q_{t} / Q_{\infty}=K t^{n}$} & $R^{2}$ \\
& $R^{2}$ & $K$ & $R^{2}$ & $K$ & $R^{2}$ & $K$ & $R^{2}=A e^{\alpha t}+B e^{\beta t}$ \\
\hline F7 & 0.850 & 0.072 & 0.990 & 0.221 & 0.971 & 0.288 & 0.888 & 0.638 & 0.995 \\
F9 & 0.873 & 0.072 & 0.992 & 0.204 & 0.977 & 0.287 & 0.934 & 0.639 & 0.988 \\
F10 & 0.598 & 0.060 & 0.945 & 0.283 & 0.831 & 0.266 & 0.801 & 0.337 & 0.998 \\
F12 & 0.637 & 0.061 & 0.937 & 0.234 & 0.858 & 0.265 & 0.811 & 0.374 & 0.999 \\
\hline
\end{tabular}

Noted " $Q_{t}$ " and " $Q_{\infty}$ " are accumulative release rates of CPFX in CCC NPs at time " $t$ " and " $\infty$ ".

The correlation coefficient $\left(R^{2}\right)$ was closer to 1 , the fitting effect was better. As shown in Table 3, release rate and time had good relationship fitted by using equations among which double exponential equation having the highest value of $R^{2}$ was the best to describe the drug release behavior. Drug was released rapidly in the initial stage and restricted into the medium at significantly slower drug release rate in the next period.

3.5. Antibacterial Activity against Escherichia coli ATCC25922 In Vitro. The MIC of CPFX and CCC NPs was 0.16 and $0.08 \mu \mathrm{g} / \mathrm{mL}$. Compared with free ciprofloxacin, antibacterial activity of ciprofloxacin loaded in nanoparticles was increased by 2 times. Killing curve of free or ciprofloxacin in nanoparticles against Escherichia coli ATCC-25922 is shown in Figure 4. Sterilization time of free CPFX and CCC NPs at the same concentration was $8 \mathrm{~h}$ and $4 \mathrm{~h}$. It demonstrated that compared with free CPFX, CCC NPs tended to kill more bacteria and shortened the time of sterilization.

3.6. Cell Viability Assays of Drug-Free Nanoparticles. Drugfree nanoparticles were incubated with cells for $24 \mathrm{~h}$, and MTT assay was used to evaluate the cell viability at different concentrations of CMC. It can be seen from Figure 5 that drug-free nanoparticles with different concentrations of CMC showed no obvious cell inhibition within $24 \mathrm{~h}$, and 


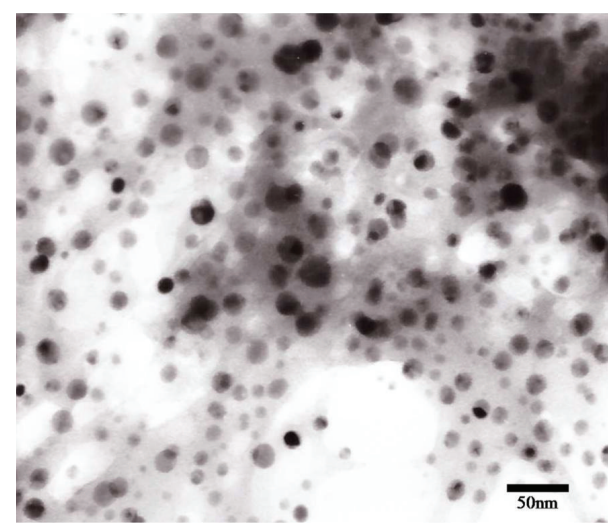

FIgURE 2: Transmission electron microscopy image of CCC NPs.

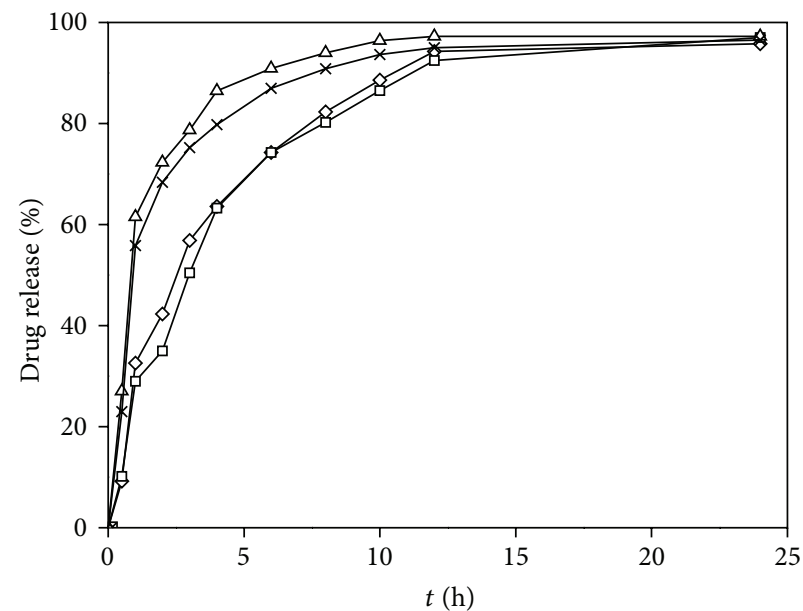

FIgURE 3: Release profiles of CPFX from nanoparticles $(\mathrm{F} 10=\Delta$, $\mathrm{F} 12=\times, \mathrm{F} 9=\diamond, \mathrm{F} 7=\square)(n=3)$.

the cell survival rate in all samples was above 95\%. This demonstrates that CMC is biocompatible at the dosage of 0.1$2.4 \mathrm{mg} / \mathrm{mL}$.

3.7. In Vitro Cellular Uptake of CCC NPs. Uptake of CCC NPs on cells is shown in Figure 6. After cells and FITClabeled CCC NPs were incubated for $8 \mathrm{~h}$, FITC showed high fluorescence intensity in cells, which demonstrated that FITC-labeled CCC NPs were internalized into the cells. As CCC NPs show higher uptake into cells, they may be good carriers for delivery of antibiotic drug.

\section{Discussion}

Compared with formulation optimization by using uniform design method which aims at investigating effects of single factor on the preparation of nanoparticles, Box-Behnken response surface method not only ensures measurement accuracy, but also studies interacting effects among different actors [15]. The results show that the predicted OD value of the optimizing formulation is similar with actual

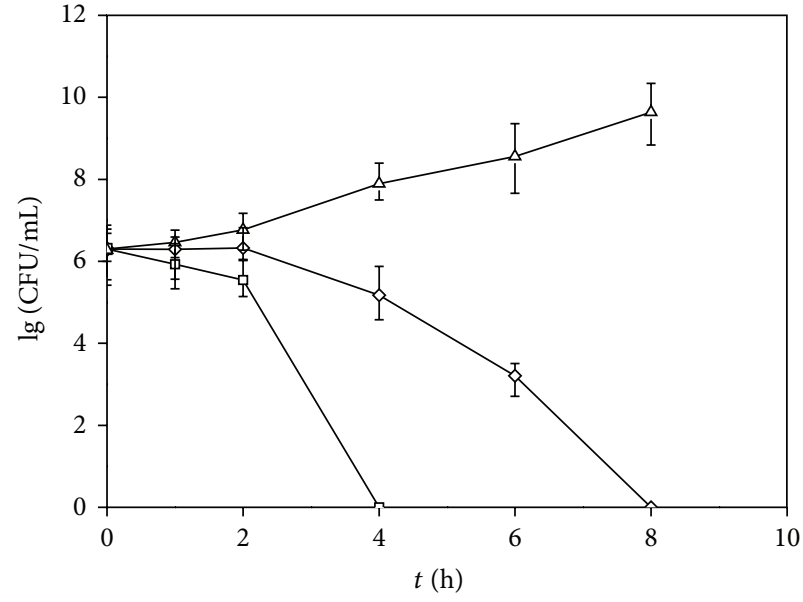

FIGURE 4: Killing profiles of free CPFX or CCC NPs against Escherichia coli ATCC-25922 (control $=\Delta$, free CPFX $=\diamond$, CCC $\mathrm{NPs}=\square)(n=3)$.

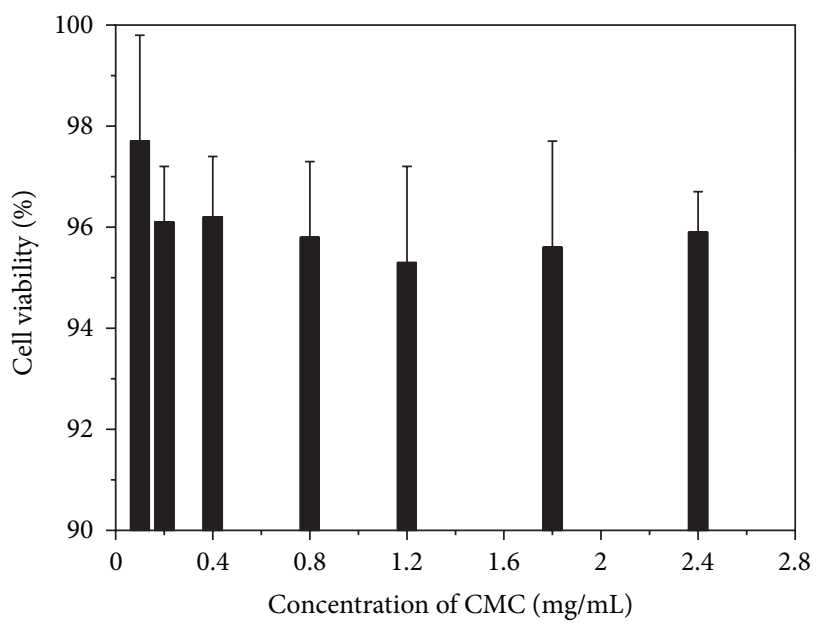

FIGURE 5: In vitro viability of SMMC-7221 cells cultured with different concentrations of CMC for $24 \mathrm{~h}(n=3)$.

result, implying that the established mathematical model by using Box-Behnken response surface method has a good predictability $[16,17]$.

CCC NPs showed different releasing pattern in the different stage. It implied that drugs absorbing on the surface of nanoparticles detached into the releasing medium rapidly, resulting in the burst release of drug in the initial stage. As more holes were formed by further degradation and dissolution of CMC into the medium, drug moved through inside pores in nanoparticles slowly and fell into the medium by diffusion.

Endocytosis is considered to be the main mechanism of cellular uptake of CCC NPs. Nanoparticles were recognized with the mediation of the opsonin and boud with cell plasma membrane. Part of the plasma membrane invaginated to form vesicles in which nanoparticles were wrapped and were separated from plasma membrane into the interior of the 


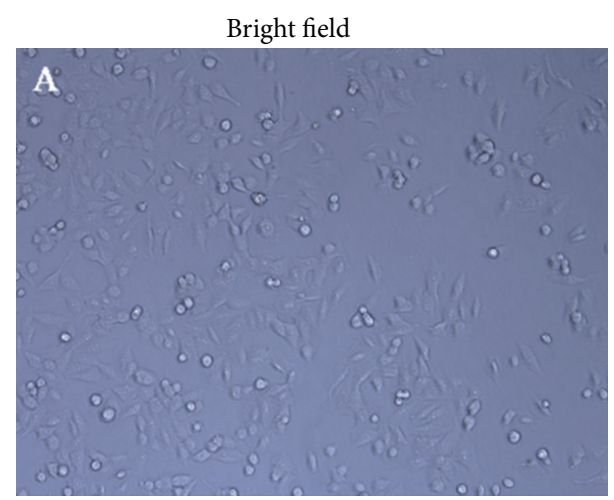

(a)

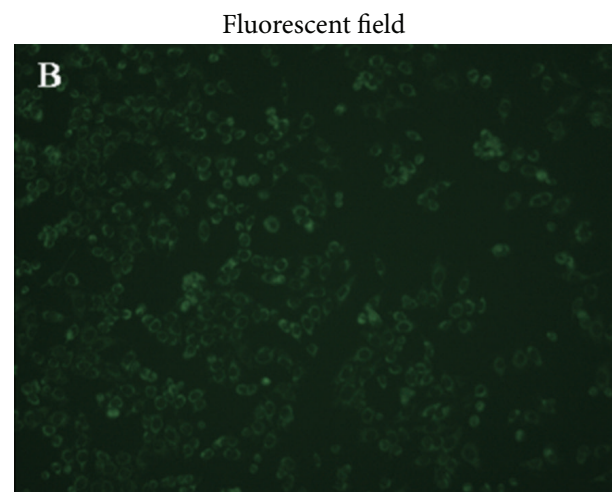

(b)

FIGURE 6: Evaluation of cellular uptake (internalization). FITClabeled CCC NPs were incubated with SMMC-7221 liver carcinoma cells for $8 \mathrm{~h}$ at $37^{\circ} \mathrm{C}$.

cell. When vesicles further contacted with lysosome, drug in vesicles was released into cytoplasm by enzymatic hydrolysis.

\section{Conclusion}

Formulation for ciprofloxacin-loaded carboxymethyl chitosan nanoparticles was optimized by using Box-Behnken response surface method. Under the optimized condition, the average value of hydrated diameter was $(151 \pm 5.67) \mathrm{nm}$, zeta potential was $(-22.9 \pm 2.21) \mathrm{mV}$, drug loading efficiency was $(76.0 \pm 4.31) \%$, drug encapsulation efficiency was $(92.3 \pm$ $7.21) \%$, and OD was $(83.8 \pm 5.11) \%$. Antibacterial activity of ciprofloxacin loaded in nanoparticles was increased by 2 times. The carrier material had good biocompatibility, and no significant cytotoxicity was observed after incubating ciprofloxacin-free nanoparticles with SMMC-7221 liver carcinoma cells. Furthermore, CCC NPs showed obvious cellular uptake, thereby improving the antimicrobial drug permeability.

\section{Conflict of Interests}

The authors declare that there is no conflict of interests with the trademarks mentioned in the paper.

\section{Authors' Contribution}

L. Zhao and B. Zhu contributed equally to this work.

\section{Acknowledgments}

This work is supported by grants from Liaoning Medical University, China. The authors thank Dr. Rongjian Su for kindly providing SMMC-7221 liver carcinoma cells and Dr. Zhenhua Chen for helpful discussions, both from Liaoning Medical University.

\section{References}

[1] E. Huczko, B. Conetta, D. Bonner et al., "Susceptibility of bacterial isolates to gatifloxacin and ciprofloxacin from clinical trials 1997-1998," International Journal of Antimicrobial Agents, vol. 16, no. 4, pp. 401-405, 2000.

[2] Q. Zheng, H. Wu, J. Du, S. Li, and Y. Yan, "The bacterial inhibitory ability and in vivo drug release pattern of a new drug delivery system: ciprofloxacine/tricalcium phosphate delivery capsule," Journal of Tongji Medical University, vol. 18, no. 3, pp. 172-176, 1998.

[3] Y. Tang and K. Gan, "Statistical evaluation of in vitro dissolution of different brands of ciprofloxacin hydrochloride tablets and capsules," Drug Development and Industrial Pharmacy, vol. 24, no. 6, pp. 549-552, 1998.

[4] M. A. Horwitz, "Phagocytosis of microorganisms," Reviews of Infectious Diseases, vol. 4, no. 1, pp. 104-123, 1982.

[5] S. Majumdar, D. Flasher, D. S. Friend et al., "Efficacies of liposome-encapsulated streptomycin and ciprofloxacin against Mycobacterium avium-M. intracellulare complex infections in human peripheral blood monocyte/macrophages," Antimicrobial Agents and Chemotherapy, vol. 36, no. 12, pp. 2808-2815, 1992.

[6] A. Di Martino, M. Sittinger, and M. V. Risbud, "Chitosan: a versatile biopolymer for orthopaedic tissue-engineering," Biomaterials, vol. 26, no. 30, pp. 5983-5990, 2005.

[7] V. R. Sinha, A. K. Singla, S. Wadhawan et al., "Chitosan microspheres as a potential carrier for drugs," International Journal of Pharmaceutics, vol. 274, no. 1-2, pp. 1-33, 2004.

[8] A. Grenha, C. I. Grainger, L. A. Dailey et al., "Chitosan nanoparticles are compatible with respiratory epithelial cells in vitro," European Journal of Pharmaceutical Sciences, vol. 31, no. 2, pp. 73-84, 2007.

[9] L. Illum, "Chitosan and its use as a pharmaceutical excipient," Pharmaceutical Research, vol. 15, no. 9, pp. 1326-1331, 1998.

[10] I. M. van der Lubben, J. C. Verhoef, G. Borchard, and H. E. Junginger, "Chitosan and its derivatives in mucosal drug and vaccine delivery," European Journal of Pharmaceutical Sciences, vol. 14, no. 3, pp. 201-207, 2001.

[11] D. C. Montgomery, "Response surface methodology," in Design and Analysis of Experiments, D. C. Montgomery, Ed., pp. 445474, John Wiley \& Sons, New York, NY, USA, 2nd edition, 1984.

[12] J. Hao, X. Fang, Y. Zhou et al., "Development and optimization of solid lipid nanoparticle formulation for ophthalmic delivery of chloramphenicol using a Box-Behnken design," International Journal of Nanomedicine, vol. 6, pp. 683-692, 2011.

[13] G. Y. Li, M. Zhong, Z. D. Zhou, Y. D. Zhong, P. Ding, and Y. Huang, "Formulation optimization of chelerythrine loaded $\mathrm{O}$-carboxymethylchitosan microspheres using response 
surface methodology," International Journal of Biological Macromolecules, vol. 49, no. 5, pp. 970-978, 2011.

[14] E. E. Hassan, R. C. Parish, and J. M. Gallo, "Optimized formulation of magnetic chitosan microspheres containing the anticancer agent, oxantrazole," Pharmaceutical Research, vol. 9, no. 3, pp. 390-397, 1992.

[15] I. Steinhauser, B. Spänkuch, K. Strebhardt, and K. Langer, "Trastuzumab-modified nanoparticles: optimisation of preparation and uptake in cancer cells," Biomaterials, vol. 27, no. 28, pp. 4975-4983, 2006.

[16] S. Sharma, A. Malik, and S. Satya, "Application of response surface methodology (RSM) for optimization of nutrient supplementation for $\mathrm{Cr}(\mathrm{VI})$ removal by Aspergillus lentulus AML05," Journal of Hazardous Materials, vol. 164, no. 2-3, pp. 1198-1204, 2009.

[17] M. A. Bezerra, R. E. Santelli, E. P. Oliveira, L. S. Villar, and L. A. Escaleira, "Response surface methodology (RSM) as a tool for optimization in analytical chemistry," Talanta, vol. 76, no. 5, pp. 965-977, 2008. 

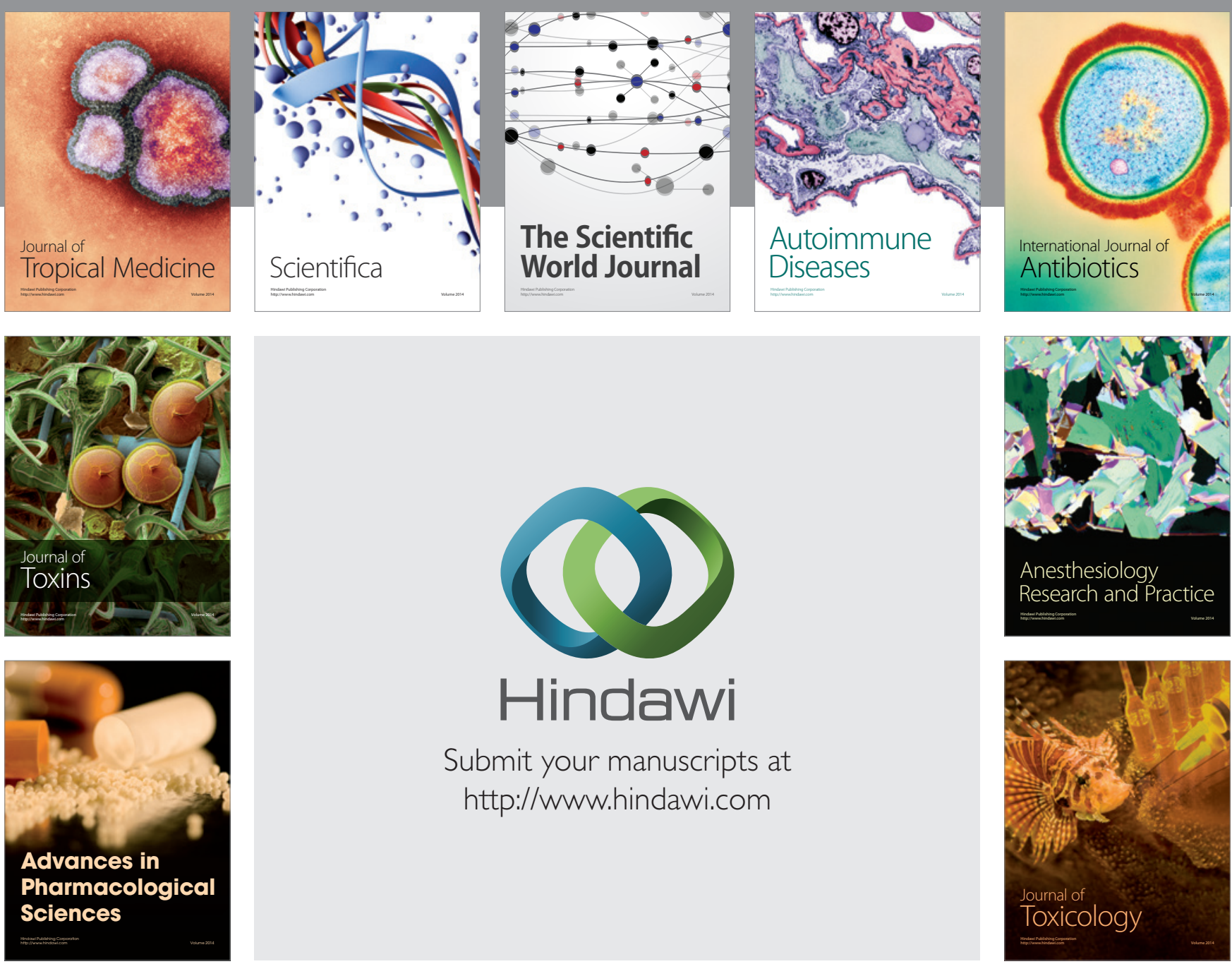

\section{Hindawi}

Submit your manuscripts at

http://www.hindawi.com
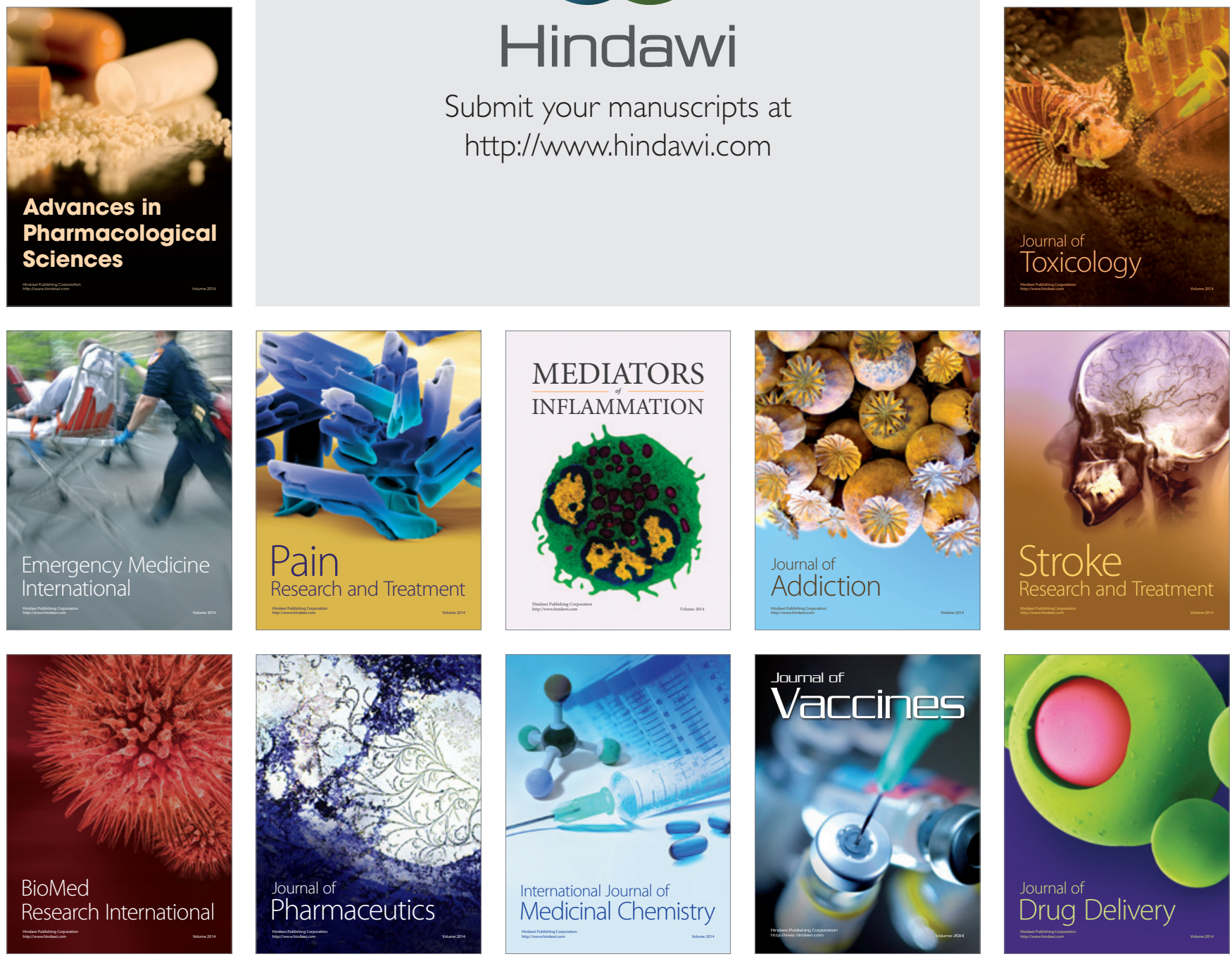